\title{
Stress-Induced Transformation and Temperature-Induced Transformation in Cu-Zn-Al Single Crystals
}

M.-P. Baron and M. Morin

INSA de Lyon, G.E.M.P.P.M., bâtiment 502, 20 avenue Albert Einstein, 69621 Villeurbanne, France

\begin{abstract}
The stress-induced martensitic transformation has been studied at different temperatures $\mathrm{T}>\mathrm{Ms}$. The application of a stress $\sigma$ on a shape memory alloy leads to the apparition of oriented variants of martensite in the direction of the stress. It causes the superelastic effect. Beyond a critical stress $\sigma_{c}$, variants grow until parent phase diseappears. But martensitic transformation can be also induced by temperature.

During a superelastic test, the sample has been overheat, then cooled at a constant deformation. It could be noticed that stress moves with temperature and that a low hysteresis appeared.
\end{abstract}

\section{INTRODUCTION}

A number of investigation have been carried out about the martensite transformation because of interest of shape memory phenomena and its properties as shape memory effect, two way shape memory, nubberlike behaviour and superelasticity. The shape memory alloys presents an ability to undergo a thermoelastic martensitic transformation[1,2]. The thermoelastic martensitic transformation can be induced by a temperature variation. However, it is also common for a similar form of martensite to be induced by an applied stress and to shrink when the load is removed. It is implicit that the transformation is reversible but includes a hysteresis of about $3 \mathrm{MPa}$. The superelasticity phenomenon observed above Ms temperature is due to the formation of stress-induced martensite on a load cycling. In order to study the superelasticy and the connexion existing between stress-induced martensite and temperature-induced martensite, a tensile machine was required.

The purpose of the present paper is to report the results of the mechanical studies and to verify the stress behaviour versus temperature.

\section{EXPERIMENTAL}

The samples are $\mathrm{CuZnAl}$ single crystals, containing $15,5 \%$ wt $\mathrm{Zn}$ and $8 \%$ wt Al. Polycrystals are obtained by melting in an induction furnace with nitrogen protection and then single crystals are obtained by a Bridgman method. Specimen for tensile tests were cut, the gauge lengh portion being $15 \times 1 \times 3.5 \mathrm{~mm}^{3}$. The Ms temperature is $14^{\circ} \mathrm{C}$. The heat treatment consisted of a homogenization 10 minutes at $850^{\circ} \mathrm{C}$, a quench in water and an ageing in boiled water 30 minutes in order to cancel vacancies and in order to obtain a beta phase with a $\mathrm{DO}_{3}$ order $[3,4,5]$.

A tensile machine has been designed in order to obtain data on shape memory behavior [6]. It is driven by a computer. Its characteristics are:

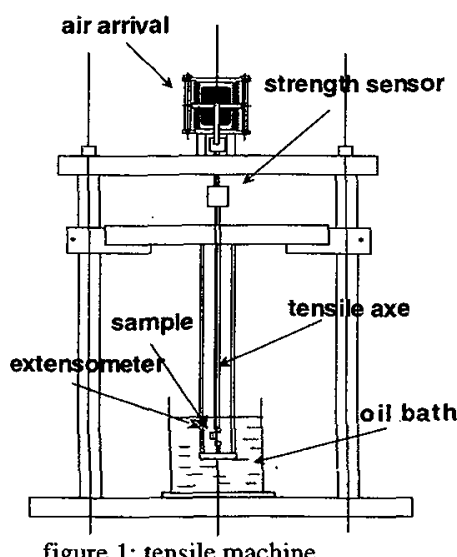

figure 1: tensile machine 
- a pneumatic controlled movement

- an uniaxial (vertical) motion

- an absence of external friction

An electrovalve controls the air arrival between two inox chambers. The sensors are:

- a strenght gauge, with working limits of $0-500 \mathrm{~N}$

- a classical linear velocity displacement transducer (LVDT)

- an extensometer, associated with the sample.

This tensile machine (figure 1) can work in a strain controlled regime (with an infinite stiffness between 0 and $500 \mathrm{~N}$ ) or in a stress controlled regime (with no stiffness). The sample is immersed in a silicone oil bath in order to obtain a constant and homogeneous temperature.

Under a strain controlled regime, a constant strain rate $(2 \% / \mathrm{mn})$ is imposed and the variation of the stress is measured as a function of strain. The computer records stress, strain and temperature.

\section{RESULTS AND DISCUSSION}

The CuZnAl specimen exhibits a superelastic effect. In figure 2 a strain-stress curve is plotted, at a temperature of $\mathrm{T}=21^{\circ} \mathrm{C}$. Upon initial loading, sample shows an elastic behaviour (from $\mathrm{A}$ to $\mathrm{B}$ ). With further loading, before a critical stress $\sigma_{c}$, when martensite variants start their development, sample undergoes a martensitic transformation (from $B$ to $C$ ). The stress-strain relationship is very different from that of conventional polycrystalline materials. Single crystals exhibit a plateau, which presence can be explained by the growth of a single variant.

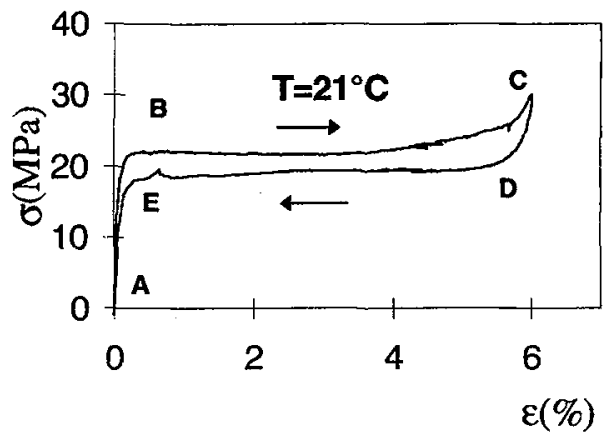

figure 2: strain-stress curve at $\mathrm{T}=21^{\circ} \mathrm{C}$

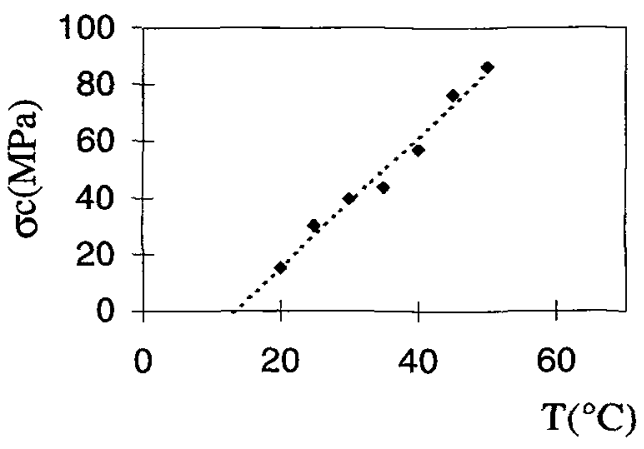

figure 3: critical stress behaviour versus temperature

Upon unloading, the stress rapidly drops at first and then becomes nearly horizontal. A hysteresis loop appears (from $C$ to $D$ ), which is characteristic of the martensite transformation. The sample undergoes a reverse transformation (from $D$ to $E$ ). Then, stress linearly decreases with strain, in an austenitic elastic return (from $\mathrm{E}$ to $\mathrm{A}$ ). Stress which is required to induce the transformation, noted $\sigma_{c}$, increases in respect with the temperature, according to the Clausius-Clapeyron law (equation $\mathrm{n}^{\circ} 1$ ).

$$
\frac{d \sigma_{c}}{d T}=\frac{\Delta S}{\varepsilon_{u}}
$$

\section{équation $\mathbf{n}^{\circ} 1$}

with $\sigma_{\mathrm{c}}$ the critical stress, $\varepsilon_{\mathrm{u}}$ the strain associated to shape change of the transformation, $\Delta S$ the entropy change per volume unit[7,8].

Figure 3 shows a straight line behaviour and a slope of about $2,3 \mathrm{MPa} /{ }^{\circ} \mathrm{C}$. The critical stress had been defined when the curve deviated from the elastic slope. It is possible to know the Ms temperature by extrapoling the line when stress upon loading becomes zero. 


\subsection{Temperature Variation experiments (TV curves)}

\subsubsection{Experimental procedure}

A sample undergoes a stress-induced transformation at a constant temperature $T_{1}$ (from A to B). The stress is released till a chosen deformation $\varepsilon_{0}$ inferior to $1 \%$ (from $\mathrm{B}$ to $\mathrm{C}$ ). Then the deformation $\varepsilon_{0}$ is remained constant and the specimen is overheated till a temperature $T_{3}$ then cooling till $T_{1}$. (from $C$ to D). The small graph on the right shows the variation of the stress versus temperature during a temperature cycle.

The results are as follows:

- from $T_{1}$ to a temperature $T_{2}<T_{3}$, an increase of the stress is observed according to a straight line behaviour.

- from $T_{2}$ to $T_{3}$, the stress remains constant and a plateau appears.

When temperature decreases, a few hysteresis appears.

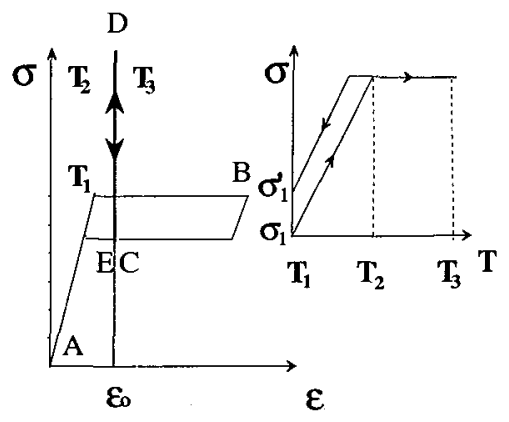

figure 4: after a superelastic cycle, a strain is held constant and the sample is overheated

\subsubsection{Results}

An exemple of superelastic effect, performed at $\mathrm{T}=21^{\circ} \mathrm{C}$ and at a strain rate of $2 \% / \mathrm{mn}$, can be noticed in figure $5 \mathrm{a}$ : the deformation $\varepsilon_{0}$ is remained constant and the specimen is overheated till a temperature of about $55^{\circ} \mathrm{C}$.

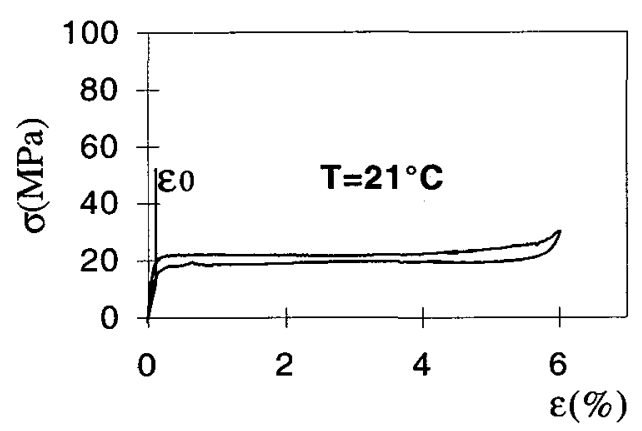

(a)

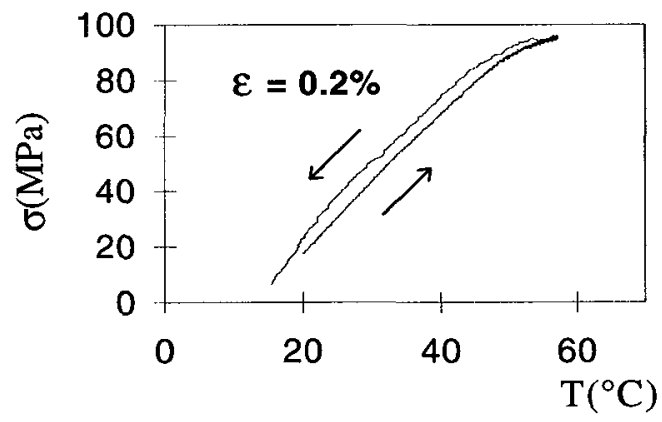

(c)

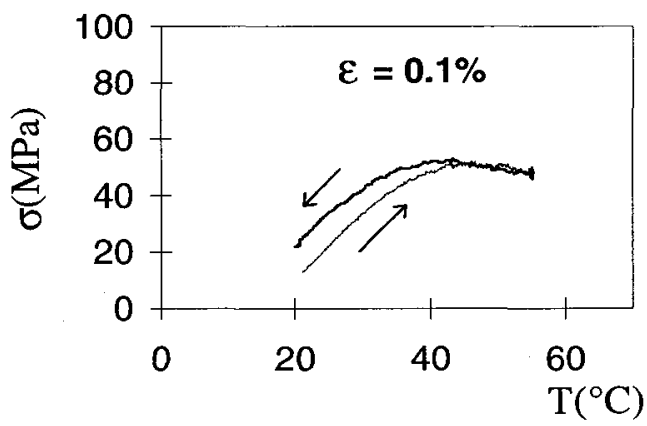

(b)

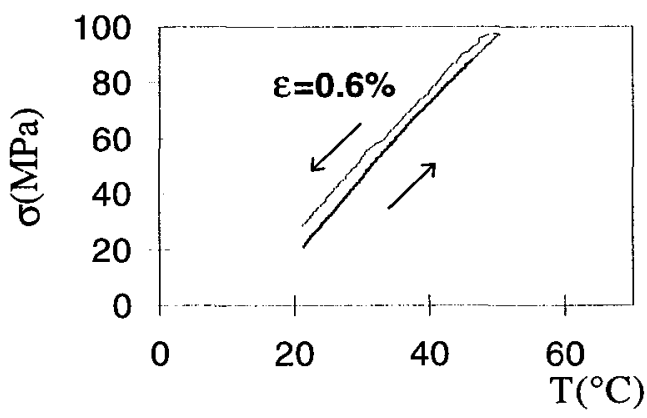

(d)

figure 5: (a) after a superelastic cycle,the deformation is held constant and the sample is overheated; (b) increase of the stress versus temperature at $0.1 \%$; (c) at $0.2 \%$ (d) at $0.6 \%$. 
The figures $5 \mathrm{~b}, 5 \mathrm{c}, 5 \mathrm{~d}$ experimentally show the evolution of the stress versus temperature for respectively $\varepsilon_{0}=0.1 \%, 0.2 \%, 0.6 \%$. When temperature increases, the sample cannot recover its high temperature shape. The reverse transformation takes place but, under a strain controlled regime, in order to keep a constant deformation, a more important stress must be generated. So, an increase of the stress is observed. Similarly, for the same reasons, cooling the sample brings about a decrease of the stress. But a small temperature hysteresis can be observed (about $2^{\circ} \mathrm{C}$ ). The slope is about $2.5 \mathrm{MPa} /{ }^{\circ} \mathrm{C}$, close to the slope measured for the critical stress.

\subsection{Constant Temperature experiments (CT curves)}

\subsubsection{Experimental procedure}

In figure 6a, strain-stress curves are plotted at different temperatures. A constant deformation was held and corresponding stress is noted for each temperature as it is drawn in figure 6b. Stress upon loading and upon unloading is reported as a function of test temperature. The plot of loading and unloading stress versus temperature results in straight lines which present a few temperature hysteresis. However, a plateau appears before a critical stress $\sigma_{0}$.

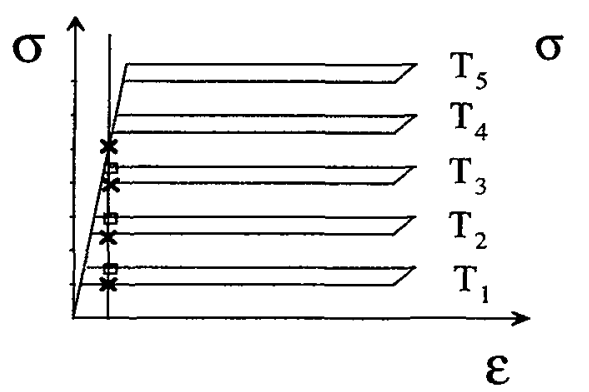

(a)

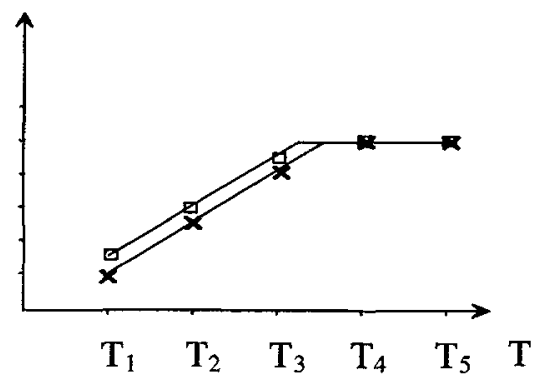

(b)

figure 6: theorical curves: (a) superelastic cycle evolves with T. A strain is held constant and corresponding stresses on loading and on unloading are collected for various temperatures; (b) On unloading stress increases as a function of the temperature and on loading stress decreases. A hysteresis appears.

\subsubsection{Results}

A constant deformation $\varepsilon_{0}=0.1 \%$ has been chosen. In figures $7 \mathrm{a}$ and $7 \mathrm{~b}$, the curves obtained by experiments are plotted. A hysteresis of about $2^{\circ} \mathrm{C}$ is found.

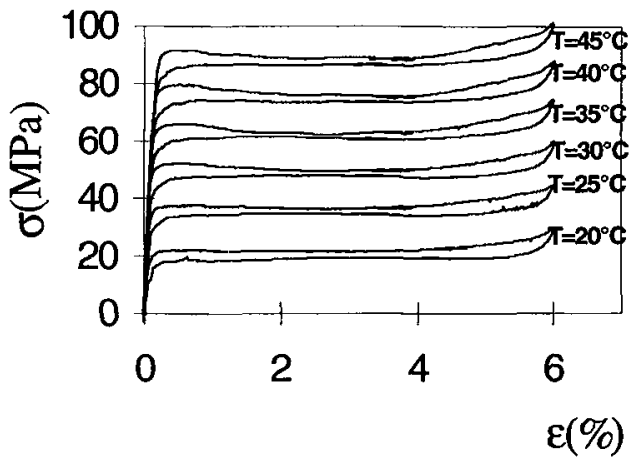

(a)

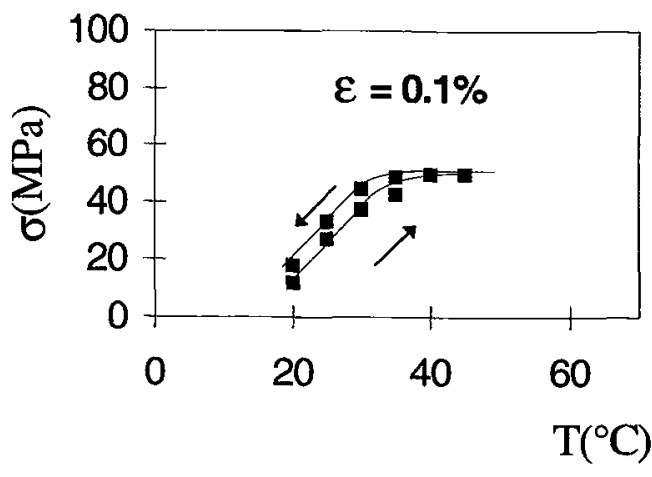

(b)

figure 7: experimental results: (a) Superelastic cycle evolution with T; (b) Stress increases versus temperature. 


\subsection{Discussion}

At $T$ above Af, the specimen is in an austenitic phase. When a strain is applied, a single variant of martensite, oriented by an uniaxial stress, appears in the single crystal. The stress-induced transformation progresses by nucleation of new plates which cross the whole specimen. The increase of the strain forces the growth of the variant plates and leads the specimen in a total martensitic phase $[9,10]$.

At $T_{1}$, when a constant strain $\varepsilon_{0}$ is applied, the sample which is submitted to a stress $\sigma_{1}$ contains a given amount $m_{1}$ of martensite plates and a given amount of austenite $a_{1}$. The sample is deformed and its length can be decomposed into two lengths $\mathrm{L}_{\mathrm{m} 1}$ and $\mathrm{L}_{\mathrm{a} 1}$ such as:

$$
\mathbf{L}_{\mathrm{m} 1}+\mathrm{L}_{\mathrm{al}}=\mathrm{L}_{0}
$$

with $\mathrm{L}_{\mathrm{m} !}$ the length component due to the martensite and $\mathrm{L}_{\mathrm{al}}$ the length component due to the austenite at $T_{1} . L_{m 1}$ is function of the amount of martensite $m_{1}$.

When the sample is overheated till a temperature $T_{2}$, superior to $T_{1}$, at $\varepsilon_{0}$ constant, the total length remains constant but stress increases as a function of the temperature as it can be noted in our experiments. At $T_{2}$, the sample undergoes a stress $\sigma_{2}$. The amount of martensite is now $\mathrm{m}_{2}$.

If total length remained constant, the martensite component and the austenite component have changed:

$$
\mathrm{L}_{\mathrm{m} 2}+\mathrm{L}_{\mathrm{a} 2}=\mathrm{L}_{0}
$$

with $\mathrm{L}_{\mathrm{m} 2}$ the length component due to the martensite and $\mathrm{L}_{\mathrm{a} 2}$ the length component due to the austenite at $T_{2}$.

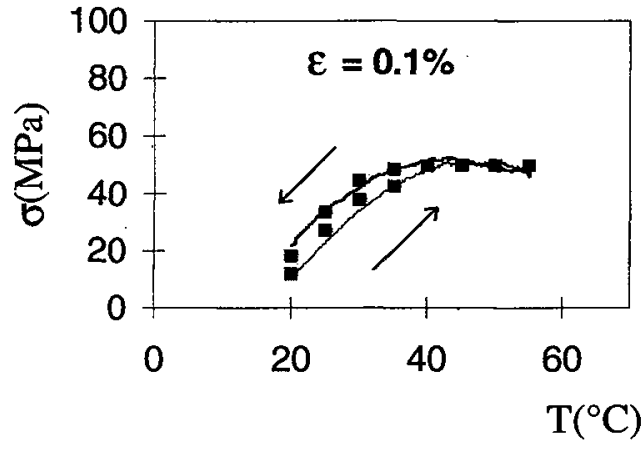

(a)

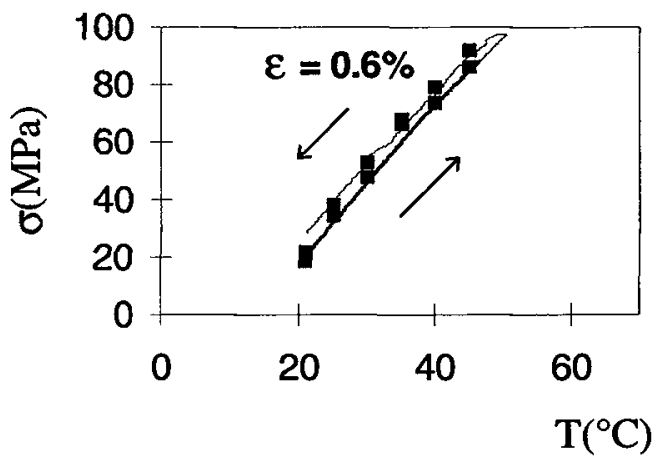

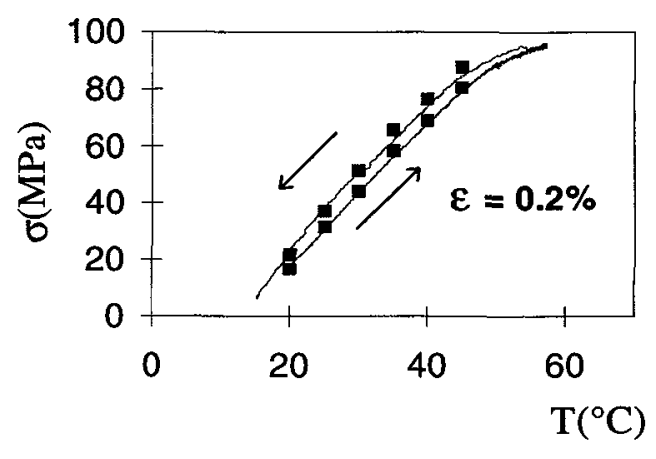

(b)

(c)

Figure 8: superposition of TV and CT curves: (a) at $0.1 \%$; (b) at $0.2 \%$; (c) at $0.6 \%$.

When the stress increases, the length of the specimen which corresponds to the austenitic phase $\mathrm{L}_{\mathrm{a}}$ increases, because of the elasticity of the austenitic phase. As the total length $\mathrm{L}_{0}$ is constant, the length which is due to the martensite phase $L_{m 1}$ decreases. So $L_{a 2}$ is higher than $L_{a 1}$ and $L_{m 2}$ is lower than $L_{m 1}$. 
Accordingly, the amount of martensite decreased and $m_{2}$ is lower than $m_{1}$. When the martensite has disappeared, the stress becomes constant.

In figure 8, the TV curves and the CT curves are superposed. As it can be seen, the two experiments made with the specimen lead to a comparable result. The effect of increasing or decreasing the applied load is respectively equivalent to cooling or heating the sample.

Figure 9 shows two stress-strain curves, performed at two temperatures $T_{2}$ and $T_{1}$, with $T_{2}>T_{1}$. However, reverse transformation plateau for the $T_{2}$ temperature corresponds with direct transformation for the $T_{1}$ temperature. At a constant deformation $\varepsilon_{0}$, loading stress, $\sigma_{1}$, at $\mathrm{T}=\mathrm{T}_{1}$, and unloading stress $\sigma_{2}$, at $\mathrm{T}=\mathrm{T}_{2}$, are the same. So, for two different temperatures, we can find the same stress. What can explain the temperature hysteresis of about $2^{\circ} \mathrm{C}$.

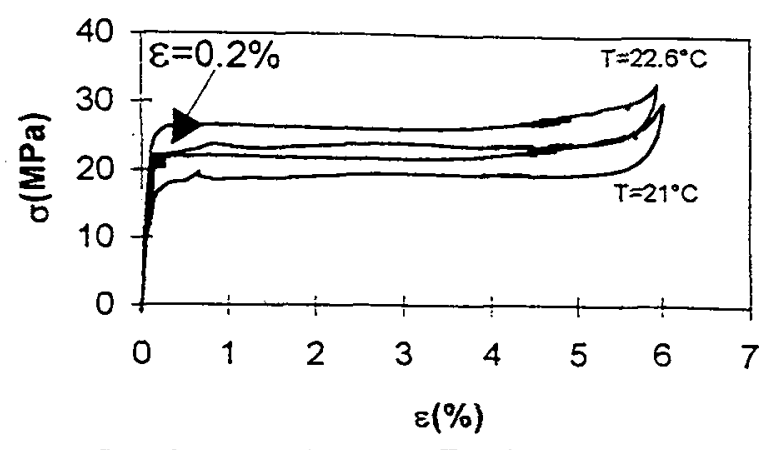

figure 9: stress-strain curves at $\mathrm{T}_{1}$ and at $\mathrm{T}_{2}$.

\section{CONCLUSION}

Superelastic effect and temperature-induced transformation have been investigated in a CuZnAl single crystal in vue to explain the similarity of both transformation. It has been shown that the stress-induced martensite can be recovered and can be reformed with a temperature variation at a constant deformation. This transformation presents a few hysteresis of about $2^{\circ} \mathrm{C}$. A similar result can be obtained by reporting the data collected on the superelastic curves measurements at constant temperatures.

\section{References}

[1] - Schroeder T.A., Cornelis I., Wayman C.M., The Shape Memory Effect and Pseudoelasticity in Polycrystalline CuZn Alloys, Metal. Trans. A, vol.7A, 1976, pp.535-553;

[2] - Perkins J., Sponholz R.O., Stress-Induced Martensitic Transformation Cycling and Two:Way Shape Memory training in CuZnAl Alloys, Metal. Trans.A, vol.15A, 1984, pp.313-321;

[3] - Lai M.O., Lu L., Lee W.H., Influence of Heat Treatment on Properties of Cu-based Shape Memory Alloy, Journal of Materials Science, vol.31, pp.1537-1543, 1996:

[4] - Contardo Laurent, Etude des traitements d'éducation, de la stabilité et de l'origine de l'effet mémoire double sens dans un alliage CuZnAl, thesis, 1988, 118p;

[5] -Rodriguez P., Etude de la fatigue thermique et thermomécanique d'une alliage à mémoire de forme haute température type CuAlNi, thesis, 1989, 203p.;

[6] - Bigeon M.J., Morin M., Superelastic Effect Fatigue in CuZnAl Wires, 4th International Conference on New Actuators, Bremen, 1994, p.357-360;

[7] - Lovey F.C., Isalgue A., Torra V., Hysteresis Loops in Stress Induced $\beta$-18R Martensite Transformation in CuZnAl, Acta Metall. Mat., vol.40, No 12, pp. 3389-3394, 1992;

[8] - Sakamoto H., Shimizu K., Experimental Investigation on Cyclic Deformation and Fatigue Behavior of Polycrystalline CuAINi Shape Memory Alloys above Ms, Transactions of the Japan Institute of Metals, vol.27, $\mathrm{n}^{\circ} 8,1986$, pp.592-600;

[9] - Pops H., Stress-Induced Pseudoelasticity in Temary CuZn Based Beta Prime Phase Alloys, Metal. Trans., vol.1, 1970, pp.251-258;

[10] - Coluzi B., Biscaniri A., Mazzolai F.M., Amplitude Dependence of Dynamic Young's Modulus of CuZnAl Alloys near Martensitic Transformation, Journal of Physique IV, vol.5, 1995, pp. C8-823, C8-828. 